\title{
How the Artificial Intelligence Tool iPGK-PseAAC is Working in Predicting lysine Phosphoglycerylation Sites in Proteins
}

\section{Kuo-Chen Chou*}

Gordon Life Science Institute, Boston, United States of America

*Corresponding author: Kuo-Chen Chou Gordon Life Science Institute, Boston, Massachusetts 02478, United States of America

\section{Short communication}

In 2017 a very powerful AI (artificial intelligence) tool has been established for predicting lysine phosphoglycerylation sites in proteins, one of the most important post modifications in proteins [1].
To see how the web-server is working, please do the following.

Step 1. Opening the web-server at you will see the top page of iPGK-PseAAC on your computer screen, as shown in Figure 1. Click on the Read Me button to see a brief introduction about this predictor.

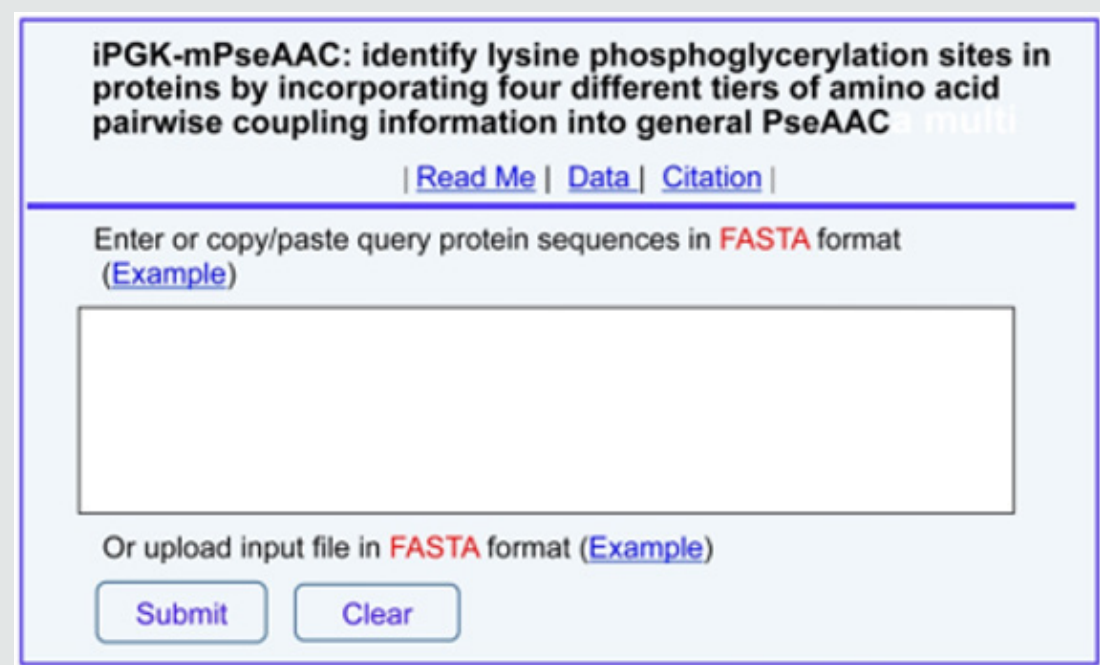

Figure 1: A semi-screenshot for the top-page of the iPGK-PseAAC web-server at (Adapted from [1] with permission).

Step 2. Either type or copy/paste your query protein sequences into the input box at the center of Figure 1. The input sequences should be in the FASTA format. For the examples of sequences in FASTA format, click the Example button right above the input box.

Step 3. Click on the Submit button to see the predicted result For example, if you use the Sequences in the Example window as the input, after a few seconds, you will see the corresponding predicted results, which is fully consistent with experiment observations.
Step 4. Click the Data button to download the benchmark dataset used in this study.

Step 5. Click the Citation button to find the relevant papers that document the detailed development and algorithm for iPGKPseAAC.

It is anticipated that the Web-Server will be very useful because the vast majority of biological scientists can easily get their desired results without the need to go through the complicated equations 
in [1] that were presented just for the integrity in developing the predictor. Also, note that the web-server predictor has been developed by strictly observing the guidelines of "Chou's 5-steps rule" and hence have the following notable merits (see, e.g., [2-4] and three comprehensive review papers [5-7]): (1) crystal clear in logic development, (2) completely transparent in operation, (3) easily to repeat the reported results by other investigators, (4) with high potential in stimulating other sequence-analyzing methods, and (5) very convenient to be used by the majority of experimental scientists. It has not escaped our notice that during the development of iDNA6mA-PseKNC web-server, the approach of general pseudo amino acid components [8] or PseAAC [9] had been utilized and hence its accuracy would be much higher than its counterparts, as concurred by many investigators [10-12]. For the marvelous and awesome roles of the "5-steps rule" in driving proteome, genome analyses and drug development, see a series of recent papers [13-34] where the rule and its wide applications have been very impressively presented from various aspects or at different angles.

\section{References}

1. Liu LM, Xu Y, Chou KC (2017) iPGK-PseAAC: identify lysine phosphoglycerylation sites in proteins by incorporating four different tiers of amino acid pairwise coupling information into the general PseAAC. Med Chem 13(6): 552-559.

2. Barukab O, Khan YD, Khan SA, Chou KC (2019) iSulfoTyr-PseAAC: Identify tyrosine sulfation sites by incorporating statistical moments via Chou's 5-steps rule and pseudo components. Current Genomics 20(4).

3. Wiktorowicz A, Wit A, Dziewierz A, Rzeszutko L, Dudek D, et al. (2019) Calcium Pattern Assessment in Patients with Severe Aortic Stenosis Via the Chou's 5-Steps Rule, Current Pharmaceutical Design 25(35): 37693775 .

4. Vishnoi S,Garg P, Arora P (2020) Physicochemical n-Grams Tool: A tool for protein physicochemical descriptor generation via Chou's 5-step rule, Chem Biol Drug Des 95(1): 79-86.

5. Chou KC (2011) Some remarks on protein attribute prediction and pseudo amino acid composition (50th Anniversary Year Review, 5-steps rule). J Theor Biol 273(1): 236-247.

6. Chou KC (2019) Advance in predicting subcellular localization of multilabel proteins and its implication for developing multi-target drugs. Current Medicinal Chemistry 26(20).

7. Chou KC (2019) Impacts of pseudo amino acid components and 5-steps rule to proteomics and proteome analysis.Current Topics in Medicinak Chemistry (CTMC) In: Special Issue (Eds.), G.P Zhou 19(25).

8. Chou KC (2001) Prediction of protein cellular attributes using pseudo amino acid composition. Proteins 43(3): 246-255.

9. Chou KC (2005) Using amphiphilic pseudo amino acid composition to predict enzyme subfamily classes. Bioinformatics 21(1): 10-19.

10. Kandaswamy KK, Pugalenthi G, Moller S, Hartmann E, Kalies KU,et al. (2010) Prediction of Apoptosis Protein Locations with Genetic Algorithms and Support Vector Machines Through a New Mode of Pseudo Amino Acid Composition. Protein and Peptide Letters 17(12): 1473-1479.

11. Mohabatkar H (2010) Prediction of cyclin proteins using Chou's pseudo amino acid composition. Protein \& Peptide Letters 17(10): 1207-1214.

12. Nanni L, Brahnam S, Lumini A (2010) High performance set of PseAAC and sequence based descriptors for protein classification. J Theor Biol 266(1): 1-10.
13. Chou KC (2019) The cradle of Gordon Life Science Institute and its development and driving force. Int J Biol Genetics 23(5): 1-28.

14. Chou KC (2019) Showcase to illustrate how the web-server iDNA6mAPseKNC is working. Journal of Pathology Research Reviews \& Reports 1(1): 1-15.

15. Chou KC (2019) The pLoc_bal-mPlant is a Powerful Artificial Intelligence Tool for Predicting the Subcellular Localization of Plant Proteins Purely based on their Sequence Information, Int J Nutr Sci 4: 1-4.

16. Chou KC, Cheng X, Xiao X (2019) pLoc_bal-mEuk: predict subcellular localization of eukaryotic proteins by general PseAAC and quasibalancing training dataset. Med Chem 5(5):472-485.

17. Chou KC (2019) Showcase to illustrate how the web-server iNitro-Tyr is working. Glo J of Com Sci and Infor Tec 2: 1-16.

18. Chou KC (2019) Gordon Life Science Institute: Its philosophy, achievements, and perspective, Annals of Cancer Therapy and Pharmacology.

19. Chou KC (2020) Showcase to Illustrate how the webserver pLoc_balmEuk Is working. Biomed J Sci \& Tech Res 24(2).

20. Chou KC (2019) The pLoc_bal-mGneg Predictor is a Powerful WebServer for Identifying the Subcellular Localization of Gram-Negative Bacterial Proteins based on their Sequences Information Alone. Ann Agric Crop Sci 2019 4(4): 1054.

21. Chou KC (2020) How the artificial intelligence tool iRNA-2methyl is working for RNA 2'-Omethylation sites, Journal of Medical Care Research and Review 3: 348-366.

22. Chou KC (2020) Showcase to illustrate how the web-server iKcr-PseEns is working. Journal of Medical Care Research and Review 9(1): 85-89.

23. Chou KC (2020) The pLoc_bal-mVirus is a powerful artificial intelligence tool for predicting the subcellular localization of virus proteins according to their sequence information alone. J Gent \& Genome.

24. Chou KC (2019) How the artificial intelligence tool iSNO-PseAAC is working in predicting the cysteine S-nitrosylation sites in proteins. J Stem Cell Res Med 1-9.

25. Chou KC (2020) Showcase to illustrate how the web-server iRNA-Methyl is working. J Mol Genet 1-7.

26. Chou KC (2020) How the Artificial Intelligence Tool iRNA-PseU is Working in Predicting the RNA Pseudouridine Sites. Biomed J Sci \& Tech Res 24(2).

27. Chou KC (2020) Showcase to illustrate how the web-server iSNO-AAPair is working. J Gent \& Genome.

28. Chou KC (2020) The pLoc_bal-mHum is a Powerful Web-Serve for Predicting the Subcellular Localization of Human Proteins Purely Based on Their Sequence Information. Adv Bioeng Biomed Sci Res 1-5.

29. Chou KC (2020) Showcase to Illustrate How the Web-server iPTM-mLys is working. Infotext Journal of Infectious Diseases and Therapy [IJID] 1-16.

30. Chou KC (2020) The pLoc_bal-mGpos is a powerful artificial intelligence tool for predicting the subcellular localization of Gram-positive bacterial proteins according to their sequence information alone. Glo J of Com Sci and Infor Tec 2: 01-13.

31. Chou KC (2020) Showcase to illustrate how the web-server iPrenyPseAAC is working. Glo J of Com Sci and Infor Tec 2: 01-15.

32. Chou KC (2020) Some illuminating remarks on molecular genetics and genomics as well as drug development. Molecular Genetics and Genomics 295(2): 261-274.

33. Chou KC (2020) The Problem of Elsevier Series Journals Online Submission by Using Artificial Intelligence. Natural Science 12(2): 3738.

34. Chou KC (2020) The Most Important Ethical Concerns in Science. Natural Science 12(2): 35-36. 


\section{(C) This work is licensed under Creative Commons Attribution 4.0 License}

To Submit Your Article Click Here: Submit Article

DOI: $10.32474 /$ PRJFGS.2020.04.000180

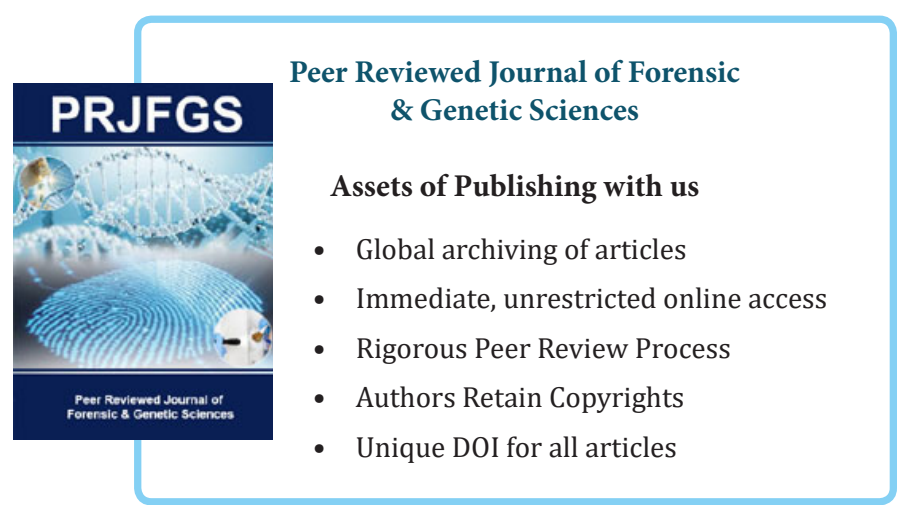

